\title{
Making the Invisible Visible: Empowering Pre-college Teachers Through Microscopic Investigations of Micro- and Nano-worlds
}

\author{
V. M. Serio, Jr.*, K. D. Moulton*, J. L. Jamison*, G. Fletcher*, L. Flower**, and S. M. Duboise* \\ * Department of Applied Medical Sciences, University of Southern Maine, 96 Falmouth Street, 178 \\ Science Bldg., Portland, ME 04103 \\ ** Farmington River Regional School District, 555 North Maine Road, Otis, MA 01253
}

The microscopic world provides teachers with excellent opportunities to develop hands-on, inquirybased curriculum, yet many K-12 educators lack the knowledge, equipment and skills necessary to engage their students in these types of explorations. Through a Science Education Partnership Award (SEPA) from the National Institutes of Health (NIH), National Center for Research Resources (NCRR), researchers at the University of Southern Maine (USM) are offering professional development activities designed to build skills in microbiology, immunology, nanotechnology and microscopy, subjects that are notably underrepresented in the K-12 curriculum and in the undergraduate education of many teachers $[1,2]$. As a result of lacking formal microbiology training, the subject matter is often viewed as too dense, abstract, or inaccessible to be presented to pre-college students, despite the immensely important and fundamental roles microbes and viruses play in evolution, human health, and the ecology of all biomes on earth $[3,4,5,6]$. Microscopy is the essential gateway for making generally invisible micro- and nano-scale worlds visible, accessible, and less abstract for students at all levels.

Teacher professional development with the pervasive goal of making microbiology, virology, and micro- and nano-scale imaging accessible for K-12 classrooms is being pursued through two-week summer institutes and weekend academic year programs. In July 2008 the first Micro- and Nanospace Explorations of Health and Disease Summer Institute was held at USM and enrolled fourteen grade 3-8 teachers. Elementary and middle school teachers were targeted because these grade levels are critical for the development of scientific interests among the students but teachers at these levels have few classroom microscopy resources and have insufficient training in their use. Emphasis during the summer institute is on collaborative grade level appropriate curriculum development, establishing outreach partnerships throughout the academic year, and providing a light microscope with digital image capture capability for each participant's classroom. To reveal the nano-scale during the professional development, the project incorporates extensive use of electron microscopy, particularly USM's transmission electron microscope (TEM), a TECNAI G2 Spirit BioTWIN operating at $100 \mathrm{kV}$. Sessions with the teachers involved preparing specimens for TEM and then acquiring images with the scope. Teachers viewed specimens with light and electron microscopy as shown in Figure 1A where the stomata on lettuce leaf specimens are imaged by light microscopy and in Figure 1B where TEM is used to see chloroplast ultrastructure in a tomato leaf specimen. Viruses, particularly bacteriophages as shown in Figure 1C, were also important specimens for the TEM work. By arrangement with FEI Company, a benchtop scanning electron microscope (SEM, the FEI Phenom) was also used during one summer workshop day allowing the teachers to acquire images such as that of diatomaceous earth shown in Figure 1D. Initial teacher responses to both summer and academic year offerings have been highly positive. A future phase of the project will include wide dissemination of the project curriculum products and integration of academic year programs for K-12 teachers into Department of Applied Medical Sciences academic offerings. 


\section{References}

[1] M. Schaechter, R. Kolter, and M. Buckley, Microbiology in the 21st Century: Where we are and where are we going. American Academy of Microbiology, Washington, DC, 2004.

[2] M. Bloom, Frontiers in Microbiology, BSCS, Colorado Springs, CO, 2006.

[3] J. A. Fuhrman, Nature 399 (1999) 541.

[4] K. E. Wommack, and R. R. Colwell, Microbiol. Mol. Biol.Rev. 64 (2000) 69.

[5] C. A. Suttle, Nature 437 (2005) 356.

[6] M. Schaechter, J. L. Ingraham, and F. C. Neidhardt, Microbe. ASM Press, Washington, DC, 2006.

[7] This work was supported by NIH NCRR grant 1R25RR024280-01 and combined NSF (CNS0521262) and USM support for TEM. The assistance of FEI, Inc. is gratefully acknowledged.

A.

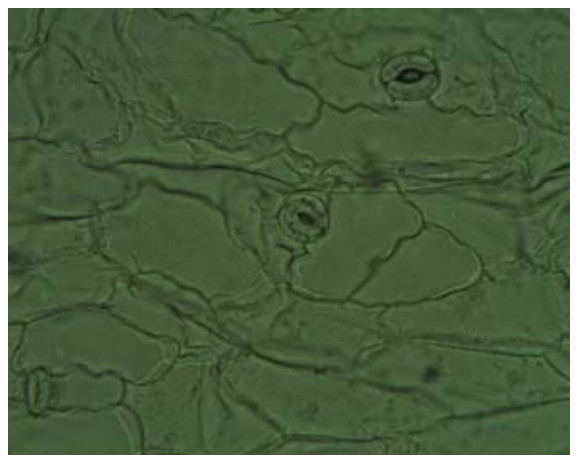

C.

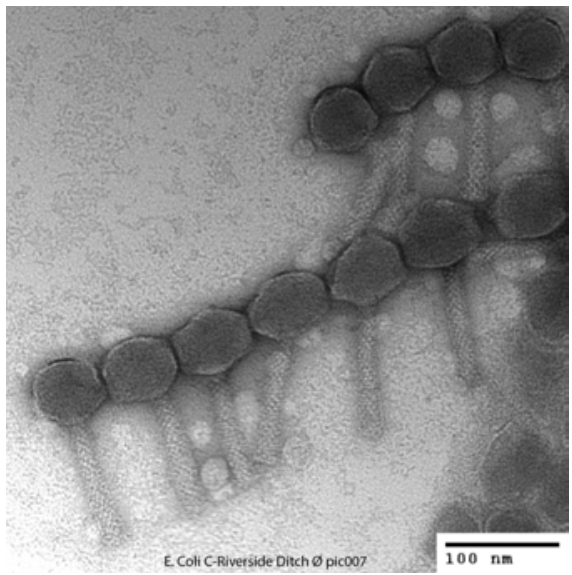

B.

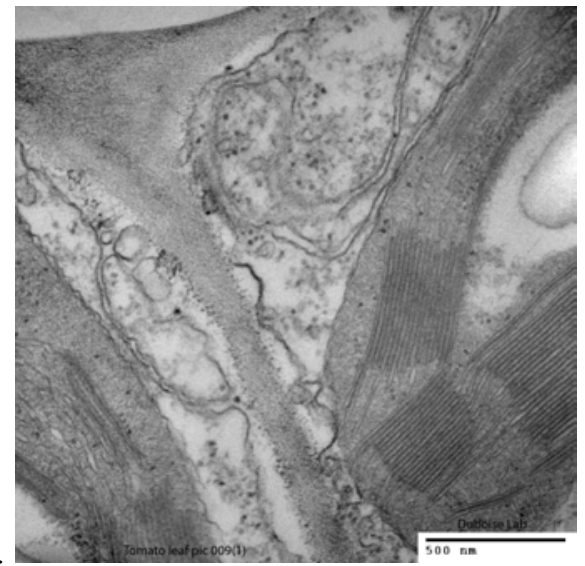

D.

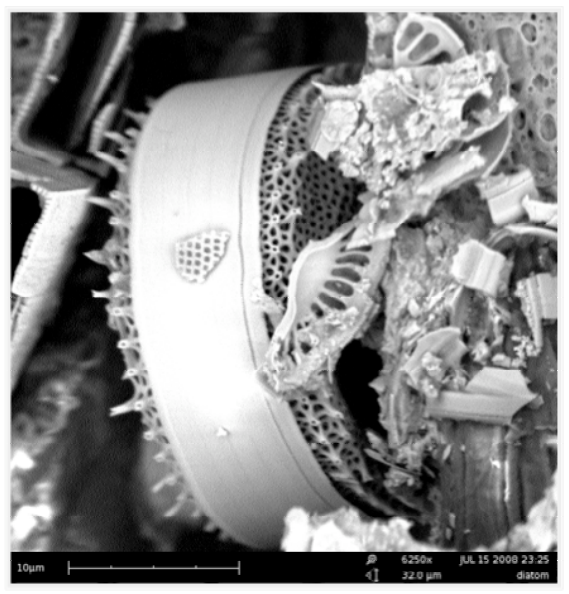

Figure 1. Light and electron micrographs acquired during the USM teacher professional development summer and academic year sessions. A. Lettuce leaf light microscopy image showing stomata in the open and closed position upon the addition of a drop of saltwater, 400x. B. TEM ultrastructural view of tomato leaf specimen showing cell wall and chloroplast thylakoid layers. C. TEM image of bacteriophages (that infect Eschericia coli, strain C) isolated by teacher participants during the Fall 2008 session. D. SEM image of diatoms acquired using the FEI Phenom during the 2008 teacher summer institute. 